\title{
PENGUKURAN ANTROPOMETRI UNTUK DESAIN PERALATAN YANG TERKAIT DENGAN TELINGA: SEBUAH SURVEI PENDAHULUAN
}

\author{
Mahrus K. Umami \\ Fakultas Teknik \\ Universitas Trunojoyo Madura \\ J1. Raya Telang, Kamal, Bangkalan 69162 \\ Email : mahrus.umami@iantrunojoyo.ac.id
}

Abstract

This study is a preliminary survey of a main study on anthropometry of ear. This study was done since the availability of ear anthropometry for Indonesian population was very limited. On the other, the availability of the ear anthropometry is very important. The current study aims to collect anthropometric data that are possible to consider in designing ear-related products. Thirty subjects aged in the range of 18-20 years old were involved in the measurement. Three dimensions of the outer ear, namely: ear hole length, ear connection length, and pinna length were measured. Result of this study shows an initial description of the outer ear dimensions that is useful in designing ear-related products, especially for Indonesian young adults.

Keywords: anthropometry, ear, design, ergonomics, earphone.

1. Pendahuluan

Saat ini sangat banyak peralatan dan produk yang dibuat untuk memudahkan manusia dalam kehidupannya sehari-hari. Semua produk seperti: pakaian, meja, kursi, kendaraan, perkakas tangan, dan sejenisnya, juga stasiun kerja, dan kantor, perlu disesuaikan dengan antropometri penggunanya [1]. Merancang produk dengan mempertimbangkan antropometri pengguna adalah sangat penting, jika tidak maka produk itu tidak akan sesuai dengan karakteristik penggunanya [2]. Pemanfaatan data antropometri dalam perancangan produk dan tempat kerja dapat menghasilkan produk yang user-friendly dan lingkungan kerja yang aman bagi pengguna [3].

Banyak sekali usaha yang telah dilakukan oleh para peneliti untuk mendapatkan data antropometri. Di antara penelitian-penelitian yang telah dilakukan itu banyak bertujuan untuk mendapatkan ukuran-ukuran pada seluruh tubuh. Sebagian yang lain mengukur secara rinci pada bagian tubuh yang spesifik, seperti: tangan, kaki, dan kepala. Ada pula penelitian-penelitian yang mengukur antropometri untuk tujuan desain produk tertentu yang diperuntukkan bagi sekelompok pengguna yang tertentu pula. Beberapa pengukuran antropometri itu di antaranya untuk desain peralatan petani di kawasan Kerala [4], Jabalpur [5], dan Gujarat Utara [6], desain peralatan pertanian untuk kawasan tenggara Nigeria [7], desain peralatan pertanian untuk orang Jawa dan Madura, Indonesia [8], dan desain peralatan pekerja kebun bunga di Columbia [9].

Untuk peralatan yang terkait dengan telinga, sampai saat ini data antropometri yang tersedia masih sangat terbatas. Namun demikian, beberapa upaya pengumpulan data sudah dilakukan oleh beberapa peneliti dari berbagai negara. Salah satu publikasi penelitian yang ditemukan pada penelusuran pustaka adalah penelitian yang dilakukan oleh Liu [10] yang mengukur tiga dimensi luar dari telinga, yaitu: panjang lubang telinga, panjang koneksi telinga, dan panjang daun telinga (pinna). Ketiga dimensi tersebut dipilih karena sangat penting untuk dipertimbangkan dalam desain produk terkait dengan telinga. Lubang telinga dipertimbangkan dalam perancangan ukuran earphone; Panjang koneksi telinga digunakan untuk perancangan bluetooth earphone; dan panjang daun telinga perlu dipertimbangkan dalam perancangan diameter dalam pada headphone [10].

Penelitian-penelitian lain mengukur dimensi-dimensi yang berbeda-beda sesuai dengan latar belakang dan tujuannya 
masing-masing. Sebagai contoh, Sforza dkk. [11] mengukur banyak dimensi pada telinga dengan tujuan untuk mengetahui variasi bentuk telinga menurut usia dan jenis kelamin. Alexander, dkk. [12] menambahkan suku sebagai sumber variasi, selain kedua faktor yang diteliti oleh Sforza, dkk [11]. Penelitian-penelitian lain dilakukan dengan melibatkan banyak dimensi yang beraneka ragam, seperti: lebar telinga $[13,14,15,16,17,18,19,20]$.

Sampai dengan saat ini, ketersediaan data antropometri telinga untuk populasi Indonesia masing sangat terbatas. Kondisi ini tidak sejalan dengan banyaknya produk terkait telinga yang beredar di masyarakat, seperti earphone, baik yang berkabel maupun yang nirkabel. Umumnya produkproduk terkait telinga tersebut diproduksi di negara lain. Dengan demikian, produkproduk itu diduga dirancang dengan tidak mempertimbangkan dimensi telinga dari populasi Indonesia. Oleh karena itu penelitian ini dimaksudkan untuk mendapatkan data awal yang menggambarkan ukuran antropometri telinga bagian luar orang Indonesia, khususnya yang tergolong berusia dewasa muda. Lebih jauh, ke depannya data yang berhasil dikumpulkan dapat dijadikan sebagai pertimbangan desain produk yang terkait dengan telinga untuk pengguna di Indonesia.

\section{Metode Penelitian}

Survei awal ini mengukur dimensi telinga dari 71 subjek (37 laki-laki) yang berusia antara 18 dan 20 tahun. Semua subjek adalah mahasiswa Universitas Trunojoyo Madura.

Pengukuran dilakukan terhadap tiga dimensi luar telinga sebagaimana yang dilakukan oleh Liu [10], yaitu: panjang lubang telinga (L1), panjang koneksi telinga (L2), dan panjang daun telinga (pinna) (L3) (Lihat Gambar 1). Pengukuran hanya dilakukan terhadap telinga bagian kanan dari setiap subjek.

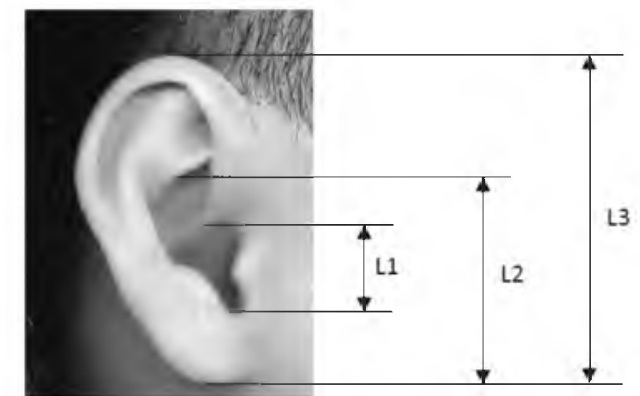

Gambar 1 Dimensi-dimensi telinga yang diukur dalam penelitian: L1 (panjang lubang telinga), L2 (panjang koneksi telinga), dan L3 (panjang telinga)

Tabel 1 Dimensi telinga subjek (dalam $\mathrm{mm}$ )

\begin{tabular}{|c|c|c|c|c|c|c|c|c|c|}
\hline \multirow{2}{*}{$\begin{array}{c}\text { Dime } \\
\text { nsi }\end{array}$} & \multicolumn{3}{|c|}{ Laki-laki } & \multicolumn{3}{c|}{ Perempuan } & \multicolumn{3}{c|}{ Keseluruhan } \\
\cline { 2 - 9 } & $\begin{array}{c}\text { Rerata } \\
\text { (SD) }\end{array}$ & $\begin{array}{c}\text { \%til ke- } \\
5\end{array}$ & $\begin{array}{c}\text { \%til ke- } \\
95\end{array}$ & $\begin{array}{c}\text { Rerata } \\
\text { (SD) }\end{array}$ & $\begin{array}{c}\text { \%til ke- } \\
5\end{array}$ & $\begin{array}{c}\% \text { \%til ke- } \\
95\end{array}$ & $\begin{array}{c}\text { Rerata } \\
\text { (SD }\end{array}$ & $\begin{array}{c}\text { \%til ke- } \\
5\end{array}$ & $\begin{array}{c}\text { \%til ke- } \\
95\end{array}$ \\
\hline L1 & $\begin{array}{c}16,82 \\
(2,09)\end{array}$ & 13,99 & 19,64 & $\begin{array}{c}18,88 \\
(2,56)\end{array}$ & 15,65 & 22,50 & $\begin{array}{c}17,81 \\
(2,53)\end{array}$ & 14,23 & 22,50 \\
\hline L2 & $\begin{array}{c}44,86 \\
(5,41)\end{array}$ & 35,74 & 52,27 & $\begin{array}{c}39,40 \\
(3,17)^{*}\end{array}$ & 36,00 & 45,88 & $\begin{array}{c}42,25 \\
(5,23)\end{array}$ & 35,92 & 51,33 \\
\hline L3 & $\begin{array}{c}63,70 \\
(5,17)\end{array}$ & 56,80 & 73,82 & $\begin{array}{c}63,10 \\
(3,06)\end{array}$ & 60,00 & 68,00 & $\begin{array}{c}63,42 \\
(4,27)\end{array}$ & 57,43 & 71,26 \\
\hline
\end{tabular}

* Data tidak berdistribusi normal pada $-=0,05$

Pengukuran dilakukan dengan metode image-based measurement. Gambar telinga diambil dengan scanner dua dimensi yang umum digunakan, Canon Lide 210. Perangkat lunak ImageJ 1.47v (diunduh dari http://rsbweb.nih.gov/ij/) digunakan untuk pengukuran.

Pada saat pengambilan gambar telinga, subjek diminta untuk duduk dan menempelkan telinganya pada permukaan scanner yang diposisikan miring. Selama proses scanning, scanner dan kepala subjek ditutup dengan kain hitam agar didapatkan gambar yang baik untuk pengukuran. Ketajaman gambar scanner diatur pada 300 dpi sehingga diperoleh kerapatan 12 pixell $\mathrm{mm}$.

Data hasil pengukuran ditampilkan dalam rata-rata, standar deviasi (SD), persentil ke-5 dan persentil ke-95. Data ditabulasi dan diolah dengan menggunakan Microsoft ${ }^{\mathrm{TM}}$ Excel 2016. Analisis statistik berupa uji 
normalitas data dengan metode Kolmogorov-Smirnov, uji kesamaan varians, dan uji $\mathrm{T}$ dua sampel dilakukan dengan bantuan Minitab 18. Kesamaan varian antara dua sampel diuji dengan uji $\mathrm{F}$ untuk data berdistribusi normal dan uji Levene untuk data berdistribusi tidak normal.

3. Hasil dan Pembahasan

\section{A. 3.1. Dimensi Telinga Subjek}

Dari data hasil pengukuran berbasis gambar pada ketiga dimensi yang telah ditentukan sebelumnya didapatkan data antropometri telinga sebagaimana ditunjukkan pada Tabel 1. Dari hasil pengujian distribusi data dengan metode Kolmogorov-Smirrnov $\quad(\square=0,05)$ didapatkan bahwa secara umum data hasil pengukuran berdistribusi normal, kecuali pada data dimensi L2 = panjang koneksi telinga, pada subjek perempuan. Besar nilai p-value pada dimensi L2 untuk subjek perempuan pada derajat keyakinan 0,95 adalah kurang dari 0,01 .
B. 3.2. Perbandingan Dimensi

Telinga Laki-laki dan Perempuan

Perbandingan antara masing-masing dimensi yang bersesuaian antara laki-laki dan perempuan secara statistik menunjukkan ada perbedaan yang signifikan pada ukuran panjang lubang telinga (L1) dan panjang koneksi telinga (L2) antara laki-laki dan perempuan. Sementara untuk panjang telinga secara statistik tidak menunjukkan adanya perbedaan yang signifikan. Tabel 2 menunjukkan ringkasan hasil analisis statistik dengan uji T satu sampel.

Dari Tabel 2 dapat dilihat bahwa dari data hasil pengukuran diperoleh ukuran panjang lubang telinga subjek laki-laki $12,24 \%$ lebih kecil daripada subjek perempuan. Sebaliknya, ukuran panjang koneksi telinga subjek laki-laki 12,18\% lebih besar daripada subjek perempuan. Sementara itu, terkait dengan ukuran panjang telinga, tidak ada perbedaan signifikan antara laki-laki dan perempuan. Namun demikian, ukuran panjang telinga subjek perempuan cenderung lebih besar daripada subjek laki-laki (Lihat Tabel 1).

Tabel 2 Perbandingan antara dimensi telinga laki-laki dan perempuan

\begin{tabular}{|c|c|c|c|c|c|c|c|c|c|l|}
\hline \multirow{2}{*}{ Dimensi } & \multicolumn{3}{|c|}{ Laki-laki } & \multicolumn{3}{c|}{ Perempaun } & \multirow{2}{*}{$\begin{array}{c}* \\
\text { perbedaan }\end{array}$} & value & $p$-value & \multirow{2}{*}{ Keterangan } \\
\cline { 2 - 10 } & Rerata & SD & Varian & Rerata & SD & Varian & & \\
\hline L1 & 16,82 & 2,09 & 4,28 & 18,88 & 2,56 & 6,51 & $-12,24$ & $-5,31$ & $<0,001$ & Berbeda signifikan \\
\hline L2 & 44,86 & 5,41 & 29,30 & 39,40 & 3,17 & 10,04 & 12,18 & $-3,92$ & $<0,001$ & Berbeda signifikan $^{\square}$ \\
\hline L3 & 63,70 & 5,17 & 26,71 & 63,10 & 3,06 & 9,38 & 0,94 & 0,6 & 0,550 & Tidak berbeda signifikan $^{\square}$ \\
\hline
\end{tabular}

${ }^{\square}$ Varian tidak sama

C. 3.3. Penerapan Data Antropometri pada Desain Produk

Secara umum setiap produk yang dibuat dengan pertimbangan antropometri pengguna dapat didasarkan pada prinsip dasar: untuk ukuran rata-rata, untuk ukuran terbesar/ terkecil, atau untuk ukuran dengan range tertentu. Hal ini penting untuk diperhatikan karena setiap produk itu harus aman dan nyaman untuk dipergunakan oleh penggunanya [21]. Oleh karena itu, kesesuaian antara produk dan antropometri pengguna merupakan faktor yang sangat penting untuk diperhatikan.

Data yang diperoleh dari pengukuran ini dapat dijadikan sebagai pertimbangan awal untuk perancangan ataupun pemilihan ukuran produk terkait telinga. Hasil pengukuran yang menunjukkan adanya perbedaan yang signifikan pada panjang lubang telinga dan panjang koneksi telinga antara subjek laki-laki dan perempuan berimplikasi pada ukuran produk yang berbeda untuk pengguna laki-laki dan perempuan.

Berdasarkan hasil pengukuran ini, diameter kepala earphone sebaiknya sama dengan dengan ukuran panjang lubang telinga (L1). Liu [10] merekomendasikan ukuran kepala earphone, yang umumnya dilapisi dengan gelang yang terbuat dari karet atau spon, dibuat sedikit lebih besar 
dari ukuran lubang telinga agar tepat menutup lubang telinga pada saat digunakan. Dengan demikian, untuk pengguna laki-laki dapat menggunakan ukuran sebesar $13,99 \mathrm{~mm}(\square 14 \mathrm{~mm})$ sebagai ukuran terkecil, sedangkan untuk pengguna perempuan ukuran direkomendasikan sebesar 15,65 mm. Apabila jenis kelamin pengguna tidak diperhatikan, maka ukuran terkecil sebesar $14,23 \mathrm{~mm}$ dapat menjadi pertimbangan. Ukuran-ukuran ini didasarkan pada data persentil ke-5 dari masing-masing kelompok data yang bersesuaian, yaitu untuk laki-laki, perempuan, dan keseluruhan sebagaimana ditunjukkan pada Tabel 1.

Untuk produk bluetooth earphone, mengikuti dimensi telinga yang menjadi pertimbangan Liu [10], maka dimensi kepalanya didasarkan pada ukuran panjang koneksi telinga (L2). Dalam hal ini, ukuran yang direkomendasikan untuk pengguna laki-laki terkecil adalah $35,74 \mathrm{~mm}$, sedangkan untuk perempuan adalah 36,00 $\mathrm{mm}$. Secara keseluruhan, tanpa memperhatikan jenis kelamin pengguna, dimensi yang direkomendasikan adalah $35,92 \mathrm{~mm}$ (Lihat Tabel 1).

Ukuran lubang dalam headphone disesuaikan dengan ukuran panjang telinga (L3) [10]. Dengan demikian, berdasarkan hasil penelitian awal ini, untuk pengguna laki-laki direkomendasikan ukuran terkecil sebesar 56,80 $\mathrm{mm}$ dan untuk pengguna perempuan setidaknya sebesar $60,00 \mathrm{~mm}$. Apabila faktor jenis kelamin tidak diperhatikan, maka untuk keseluruhan pengguna direkomendasikan ukuran terkecil 57,43 mm (Lihat Tabel 1).

\section{Kesimpulan}

Penelitian pendahuluan ini telah mengukur sejumlah kecil subjek yang berusia pada kisaran 18 sampai dengan 20 tahun. Jumlah subjek yang terlibat pada pengukuran sangat jauh dari jumlah yang mencukupi agar dapat mewakili populasi Indonesia. Namun demikian, hasil penelitian ini setidaknya sudah dapat memberikan gambaran awal mengenai antropometri telinga untuk populasi Indonesia yang sampai dengan saat ini ketersediaan datanya masih sangat terbatas.

Hasil penelitian awal ini telah menyediakan data dimensi-dimensi telinga yang dapat dijadikan sebagai pertimbangan dalam perancangan dan pemilihan produk yang terkait dengan telinga, seperti earphone, bluetooth earphone dan headphone. Dari penelitian ini didapatkan data ukuran panjang lubang telinga, panjang koneksi telinga, dan panjang telinga.

Hasil penelitian ini menunjukkan bahwa terdapat perbedaan yang signifikan pada panjang lubang telinga dan panjang koneksi telinga antara subjek laki-laki dan perempuan. Panjang lubang telinga subjek laki-laki lebih besar daripada panjang lubang telinga subjek perempuan. Sebaliknya, panjang koneksi telinga subjek laki-laki lebih kecil daripada dimensi serupa pada subjek perempuan. Penelitian ini juga menunjukkan tidak ada perbedaan signifikan pada panjang telinga subjek laki-laki dan perempuan.

\section{Saran}

Penelitian ini melibatkan sedikit sekali subjek dan dimensi pada telinga yang dimasukkan dalam pengukuran. Hal ini mungkin berakibat pada hasil penelitian yang tidak cukup mewakili populasi pengguna produk yang terkait dengan telinga di Indonesia. Oleh karena itu, maka penelitian selanjutnya diharapkan dapat melibatkan jumlah subjek yang lebih besar dan juga dimensi-dimensi yang lebih banyak lagi. Selain itu, juga memungkinkan adanya perbandingan dengan antropometri telinga dari populasi yang lain, termasuk juga perbandingan antara telinga kiri dan kanan.

6. Ucapan Terima kasih

Penulis mengucapkan terima kasih kepada Saudara Ardian Yudistira, Kartika Laila, Rofiatul Hasanah, dan Yoga Pratama bersama dengan timnya masing yang telah dengan sukarela membantu peneliti selama proses perekaman data penelitian ini.

\section{DAFTAR PUSTAKA}

[1] Wichansky, A. M., 2000, Usabilty testing in 2000 and beyond, Ergonomics, vol 43, no 7, hal 998- 
1006.

[2] Haslegrave, C. M., 1986, Characterizing the anthropometric extremes of the population, Ergonomics, vol 29, no 2, hal 281301.

[3] Prado-Lu, J. L. D., 2007, Anthropometric measurement of Filipino manufacturing workers, International Journal of Industrial Ergonomics, vol 37, no 2, hal 497503 .

[4] Sam, B., 2013, Anthropometry of Kerala female agricultural workers and design of handtools of the region, International Journal of Agricultural Engineering, vol 6, no 2, hal 453-457.

[5] Jha, A. dan Tiwari, K. B., 2014, Anthropometry of female agricultural workers Jablpur, Agriculture for Sustainable Development, vol 2, no 1, hal 62-64.

[6] Singh, S., Ahlawat, S., Pandya, S., dan Prafull, B., 2013, Anthropometric Measurements and Body Composition Parameters of Farm Women in North Gujarat, Ergonimics, vol 3, no 1, hal 1-4.

[7] Onuoha, S. N., Idike, F. I., dan Oduma, O., 2012, Anthropometry of South Eastern Nigeria Agricultural Workers, International Journal of Engineering and Technology, vol 2, no 6, hal 10891095.

[8] Wibowo, R. K. K. dan Soni, P., 2014, Anthropometry and Agricultural Hand Tool Design for Javanese and Madurese Farmers in East Java, Indonesia, APCBEE Procedia, vol 8, hal 119-124.

[9] García-Cáceres, R. G., Felknor, S., Córdoba, J. E., dan Caballero, J. P., 2012, Hand anthropometry of the Colombian floriculture workers of the Bogota plateau, International Journal of Industrial Ergonomics, vol 42, no 2, hal 183-198.

[10] B. Liu, 2008, Incorporating anthropometry into design of earrelated products, Applied Ergonomics, vol 39, no 2, hal 115121.

[11] Sforza, C., Grandi, G., Binelli, M., Tommasi, D. G., Rosati, R., dan Ferrario, V. F., 2009, Age- and sexrelated changes in the normal human ear, Forensic Science International, vol 187, hal 110.el110.e7.

[12] Alexander, K. S., Stott, D. J., Sivakumar, B., dan Kang, N., 2011, A morphometric study of the human ear, Journal of Plastic, Reconstructive \& Aesthetic Surgery, vol 64, no 1, hal 41-47.

[13] Barut, C. dan Actung, E., 2006, Anthropometric Measurements of the External Ear in a Group of Turkish Primary School Social Students, Aesthetic Plastic Surgery, vol 30, no 3, hal 255-259.

[14] Deopa, D., Thakkar, H. K., Prakash, C., Niranjan, R., dan Barua, M. P., 2012, Anthropometric measurements of external ear of medical students in Uttarakhand Region, Journal of the Anatomical Society of India, vol 62, no 1, hal 79-83.

[15] Lee, W., Jung, H., Bok, I., Kim, C., Kwon, O., Choi, T., dan You, H., 2016, Measurement and application of 3D ear images for earphone design, Proceedings of the Human Factors and Ergonomics Society 2016 Annual Meeting.

[16] Yoga, S., Balaih, J., Rangdhol, V., Vandana, S., Paulose, S., dan Kavya, L., Assessment of age changes and gender differences based on anthropometric measurements of ear: A crosssectional study, Journal of Advanced Clinical \& Research Insights, vol 4, no 4, hal 92-95.

[17] Acar, M., Alkan, S. C., Ulusoy, M., dan Akkubak, Y., 2017, Comparison of some Morphometric Parameters of the Ear on Turkish 
and African Students, Asian Journal of Biomedical and Pharmaceutical Sciences, vol 60, no 1, hal 8-12.

[18] Arora, L. dan Singh, V., 2016, Morphometric study of human auricle in the age group of 18-24 years in North West part of India, Global Journal of Medicine and Health, vol 5, no 6, hal 1-6.

[19] Taura, M. G., Adamu, L. H., dan Modibbo, M. H., 2013, External ear anthropometry among Hausas of Nigeria; the search of sexual dimorphism and correlations, World Journal of Medicine and Medical Science Research, vol 1, no 5, hal 91-95.

[20] Taura, M. G., Adamu, L. H.,
Gudaji, A., dan Modibbo, M. H., 2015, Application of external ear morphometry in age prediction: a pilot study, International Journal of Research in Medical Sciences, vol 3, no 7, hal 1775-1779.

[21] Sanders, M. S. dan McCormick, E. J., 1992, Human Factors in Engineering and Design, Singapore: McGraw-Hill, Inc. 